\title{
The Genotype Distribution of Human Papillomavirus among HIV- Infected Women Planning Pregnancy in Irkutsk, Russia
}

\author{
Elena Belyaeva*, PhD; Eleva Genich, PGS; Olga Leshchenko, PhD \\ Scientific Centre for Family Health and Human Reproduction Problems \\ Irkutsk, the Russian Federation
}

\begin{abstract}
The purpose of our research was to determine the detection frequency of 12 high-risk types of human papillomavirus (HPV) in women with human immunodeficiency virus (HIV) who are planning pregnancy and to assess the results of colposcopy and the state of the cervix in these women, depending on the presence of HPV.

Methods and Results: We examined 31 women with HIV infection who sought pregnancy-planning advice at Scientific Center for Family Health and Human Reproduction Problems in Irkutsk during 2014-2015. All HIV-infected women were tested for the presence of high-risk HPV DNA in the epithelium of the cervical canal by PCR. Material for cytological examination (PAP test) was collected during gynecological examination. PAP tests were assessed according to the Bethesda system. All changes were divided into two types: ASCUS and SIL, the last was in its turn divided into two categories: LSIL and HSIL.

The frequency of HPV detection in HIV-infected women planning pregnancy was 71\%. HPV 16 was found in 16(51.6\%) HIV-infected women and ranked first in frequency among 12 types of HPV. HPV 33 and HPV 35 were found in 15(48.4\%) and 12(38.7\%) HIV-infected women, respectively, and ranked the second and third in frequency among $12 \mathrm{HPV}$ types. We compared abnormal colposcopy results in two groups of patients with HIV infection: Group $1(\mathrm{n}=22)$ included women with HPV and Group $2(\mathrm{n}=9)$ included women without HPV. ASCUS was detected in all patients $(100 \%)$ of Group 1 and in 6(66.7\%) women of Group 2. Two women $(9.1 \%)$ from Group 1 were diagnosed with LSIL and $10(45.5 \%)$ women with HSIL.

Conclusion: HIV-infected women planning pregnancy and living in Irkutsk form a group at high-risk of HPV infection. (International Journal of Biomedicine. 2021;11(3):346-350.)
\end{abstract}

Key Words: human immunodeficiency virus $\bullet$ human papillomavirus $\bullet$ cervical cancer $\bullet$ cervical dysplasia

For citation: Belyaeva E, Genich E, Leshchenko O. The Genotype Distribution of Human Papillomavirus among HIV-Infected Women Planning Pregnancy in Irkutsk, Russia. International Journal of Biomedicine. 2021;11(3):346-350. doi:10.21103/Article11(3)_OA11

\section{Abbreviations}

ASCUS, atypical squamous cells of undetermined significance; HPV, human papillomavirus; HIV, human immunodeficiency virus; HSIL, high-grade squamous intraepithelial lesions; HAART, highly active antiretroviral therapy; LSIL, low-grade squamous intraepithelial lesions; PCR, polymerase chain reaction; SIL, squamous intraepithelial lesions.

\section{Introduction}

Irkutsk region (Eastern Siberia) has an unfavorable HIV epidemiological situation among the regions of the Russian Federation. By the end of 2016, a total of 50,344

*Corresponding author: Elena Belyaeva, PhD. Scientific Centre for Family Health and Human Reproduction Problems, Irkutsk, the Russian Federation.E-mail: belyeva_irk@mail.ru
HIV-infected people had been reported, with 3185 new cases having predominantly sexual transmission-among them, $1445(45.4 \%)$ women with an average age of $30-39$ years. HIV infection is spreading mainly among susceptible population groups: injection drug users, sex workers, men having sex with men, prisoners, and sexual partners of drug users. ${ }^{(1-3)}$ However, recent studies have corroborated the active involvement of women of reproductive age in the HIV epidemic, which was found during examinations of pregnant women. ${ }^{(4-6)}$ 
HIV infection progresses slowly, and its distinctive feature is the increasing suppression of the immune system functions, which contributes to the risk of opportunistic infections. Patients with HIV coinfection have more severe oxidative stress than HIV-monoinfected patients, which can contribute to the development of reproductive system disorders. ${ }^{(7,8)}$ Among all the variety of opportunistic infections, sexually transmitted infections, including HPV, have the most aggravating effect on reproductive health.

HPV infection is one of the most widespread sexually transmitted infections. ${ }^{(9)}$ On average, the frequency of HPV in the world is $10 \%$. The highest frequency level of HPV is observed in Africa - 22.1\%, and in Central America and Mexico - 20.4\%. In North America, Europe, and Asia, the HPV frequency is $11.3 \%, 8.1 \%$ and $8.0 \%$, respectively. ${ }^{(10)}$ There are more than 100 types of HPV that can be found in wart tissues, condylomas and other tumors; ${ }^{(11)}$ among them, about 40 types can be detected mainly in the anogenital region epithelium. HPV is divided into two groups: low- and highrisk types for cervical cancer development, and among them HPV type 16 has the greatest oncogenicity.

HPV infection among HIV-positive women is two times higher than in women without HIV infection. ${ }^{(12)}$ At the same time, HPV infection in HIV-infected women has increased pathogenicity and significantly increases the risk of cervical lesions and cancer. ${ }^{(13)}$ In HIV-infected women, it is important to assess the possible detrimental effect of opportunistic infections, including HPV, on the course of pregnancy and childbirth. $^{(14)}$

The purpose of our research was to determine the detection frequency of 12 high-risk types of HPV in women with HIV who are planning pregnancy and to assess the results of colposcopy and the state of the cervix in these women, depending on the presence of HPV.

\section{Materials and Methods}

We examined 31 women with HIV infection who sought pregnancy-planning advice at Scientific Center for Family Health and Human Reproduction Problems in Irkutsk during 2014-2015. The study was conducted in accordance with ethical principles of the WMA Declaration of Helsinki (1964, ed. 2013). Written informed consent was obtained from all participants.

The general characteristics of women with HIV infection are presented in Table 1. The average age of the women was $30.9 \pm 4.5$ years, ethnicity - Europeoids. Among 31 women, $22(71 \%)$ women had secondary special education, $9(29 \%)$ had secondary education, $7(22 \%)$ were married, $13(42 \%)$ had unregistered marriage, $2(6 \%)$ were single, and $9(30 \%)$ were divorced. Among 31 women, 22(71\%) women had regular sex, 9(29\%) women had irregular sex (less than 4 times per month); 19(61\%) women used a condom, 9(29\%) had interrupted sexual intercourse, $3(10 \%)$ did not use any contraception, and 20(64\%) women had a permanent sexual partner with HIV infection.

Patients were diagnosed with HIV in the Irkutsk Regional AIDS Center. HIV stage 4-A was found in 13(42\%) women, HIV stage 4-B in $18(58 \%)$. The average duration of HIV infection was $8 \pm 2.5$ years. Fifteen( $48 \%$ ) patients were receiving HAART. HIV was mainly transmitted sexually in $80 \%$, parenteral route of transmission of the virus was in $20 \%$.

Each patient underwent colposcopy with $5 \%$ solution of acetic acid and 5\% Lugol's iodine solution. We used the CARL ZEISS E Colposcope and the international classification of colposcopic terminology IFCPC Nomenclature (Rio de Janeiro, 2011). Material for cytological examination (PAP test) was collected during gynecological examination using vaginal specula. The impression smear was taken from the exocervix, from the border of the stratified epithelium and columnar epithelium of the cervical canal and from the lower third of the endocervix. The impression smear was obtained by scraping and was applied to the slide with a cervix brush. Further, the material was stained with hematoxylin and then with acid eosin. PAP tests were assessed according to the Bethesda system. All changes were divided into two types: ASCUS and SIL, the last was in its turn divided into two categories: LSIL and HSIL.

Table 1.

The general characteristics of women with HIV infection

\begin{tabular}{|c|c|}
\hline Women & $\mathrm{n}=31$ \\
\hline Age (years) & $30.9 \pm 4.5$ \\
\hline \multicolumn{2}{|l|}{ Education $(\%)$} \\
\hline Secondary special education & 71 \\
\hline Secondary education & 29 \\
\hline \multicolumn{2}{|l|}{ Marital status $(\%)$} \\
\hline Registered marriage & 22 \\
\hline Unregistered marriage & 42 \\
\hline in divorce & 30 \\
\hline not married & 6 \\
\hline \multicolumn{2}{|l|}{ Sexual relations $(\%)$} \\
\hline regularly & 71 \\
\hline irregularly $<4$ times a month & 29 \\
\hline \multicolumn{2}{|l|}{ Contraception $(\%)$} \\
\hline condom & 61 \\
\hline interrupted sexual intercourse & 29 \\
\hline did not use any contraception & 10 \\
\hline \multicolumn{2}{|l|}{ Stage of HIV infection } \\
\hline $4-\mathrm{A}$ & 42 \\
\hline $4-\mathrm{B}$ & 58 \\
\hline Average duration of HIV infection (years) & $8 \pm 2.5$ \\
\hline $\begin{array}{l}\text { Regularly took highly active antiretroviral } \\
\text { drugs HAART (\%) }\end{array}$ & 48 \\
\hline \multicolumn{2}{|l|}{ Way of HIV transmission (\%) } \\
\hline sexual way & 80 \\
\hline parenteral route & 20 \\
\hline
\end{tabular}

All HIV-infected women were tested for the presence of high-risk HPV DNA in the epithelium of the cervical canal by PCR. We used reagents manufactured by the Central Research Institute of Epidemiology (Russia) and followed the manufacturer's instructions. Biological material was 
sampled with the cervix brushes, which were placed in vials with transport medium (isotonic aqueous saline buffer solution with preservative). DNA was isolated from the obtained samples by sets of "DNA-Sorb-AM" reagents. We determined the presence of specific DNA segments of HPV by multiplex PCR in a thermocycler "Tertsik" (Russia), using a set of reagents "AmpliSens HPV HCR screen-Eph." Then HPV-positive samples were tested for the presence of 12 types of HPV $(16,18,31,33,35,39,45,52,56,58,59,66)$ using a set of reagents "AmpliSens HPV genotype-Eph." The results of amplification reaction amplification were estimated by electrophoresis in 3\% agarose gel, dyed with ethidium bromide.

Statistical analysis was performed using the statistical software STATISTICA (v10.0, StatSoft, USA). Baseline characteristics were summarized as frequencies and percentages for categorical variables and as means and SDs for continuous variables. Group comparisons with respect to categorical variables are performed using chi-square tests or, alternatively, Fisher's exact test when expected cell counts were less than 5 ; z-test was used to analyze the differences in proportions. A value of $P<0.05$ was considered significant.

\section{Results}

In the first stage, a screening study was conducted, which resulted in HPV detection in 22(71\%) women. In the second stage, DNA samples in which HPV was detected were additionally typed to determine the HPV genotype. In the group of HPV-positive women, on average, each patient had three different types of HPV. One or two types of virus were found in $8(36.4 \%)$ women, three or four different types in $6(27.3 \%)$ women, five or seven types were also found in $6(27.3 \%)$ women, and more than seven types of virus in $2(9.1 \%)$ women.

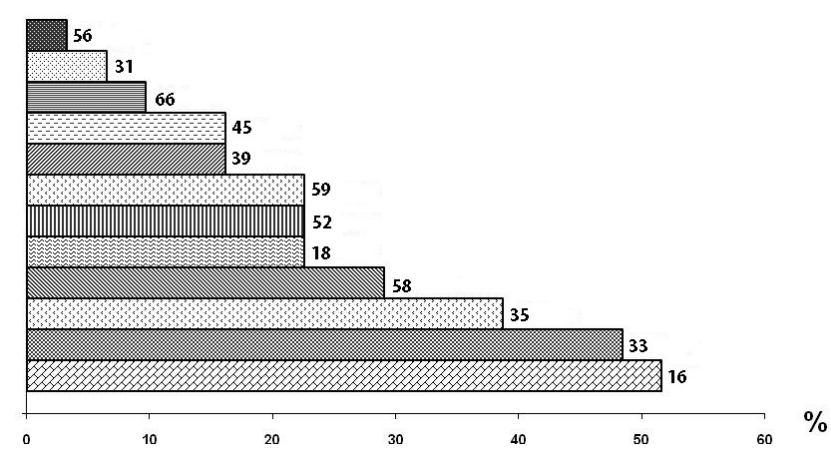

Fig. 1. The frequency of 12 types of HPV in the group of women with HIV infection, \%.

HPV 16 was found in 16(51.6\%) HIV-infected women and ranked first in frequency among 12 types of HPV (Figure 1). Only 2(12.5\%) patients had HPV 16 mono-infection, and 14(87.5\%) women had HPV 16 combined with other types of HPV. Most often, HPV 16 was combined with HPV 33 and HPV $35-12(75 \%)$ and 11(68.7\%), respectively. Only 6(37.5\%) patients with HPV 16 had combination with HPV 18.
HPV 33 and HPV 35 were found in 15(48.4\%) and 12(38.7\%) HIV-infected women, respectively, and ranked the second and third in frequency among 12 HPV types. HPV 58 was detected in $9(29 \%)$ people and ranked the fourth; the detection rates of HPV 18 and HPV 52 were the same (in 7(22.6\%) women), and they ranked fifth.

We compared abnormal colposcopy results in two groups of patients with HIV infection: Group $1(\mathrm{n}=22)$ included women with HPV and Group $2(\mathrm{n}=9)$ included women without HPV. ASCUS was detected in all patients (100\%) of Group 1 and in $6(66.7 \%)$ women of Group 2. Two women (9.1\%) from Group 1 were diagnosed with LSIL and 10(45.5\%) women with HSIL.

\section{Discussion}

The frequency of HPV detection in HIV-infected women planning pregnancy was $71 \%$. An epidemiological study previously conducted in Irkutsk showed that in the group of $641 \mathrm{HIV}$-infected women, the prevalence of HPV was $63.9 \%{ }^{(15)}$ In Russia, similar data on the prevalence of HPV infection among HIV-infected people were obtained in St. Petersburg, where 113 women with HIV infection were examined, and HPV was detected in $80.5 \%$ of them. ${ }^{(16)}$ Thus, the results of our study and other studies from other Russian regions demonstrate a high frequency of HPV in women with HIV infection.

The population-based study in Irkutsk $(\mathrm{n}=826)$ detected HPV in $37.7 \%$ of women without HIV infection. ${ }^{(17)}$ The frequency of HPV is almost two times higher in HIV-infected women in our study $\left(\chi^{2}=12.59 ; \mathrm{df}=1 ; P=0.001\right)$.

Other authors confirm data on the higher frequency of HPV infection in groups of HIV-infected women. Shipulina et al. ${ }^{(18)}$ compared the frequency of HPV between two groups of women with HIV infection $(n=155)$ and without HIV $(n=406)$ and showed that in the HIV group, HPV was detected in $38.7 \%$, and in the group without HIV, HPV was found only in $14.8 \%$ of women. In the other study, a group of women $(n=150)$ who were in prison were examined on the presence of HIV and HPV. It was shown that in the HIV group, HPV was detected in $58.2 \%$, and in the group of women without HIV - only in $23 \%{ }^{(19)}$ Thus, the results obtained in these studies showed that the prevalence of HPV infection in the group of HIV-infected women was 2.5 times higher than in the groups of women without HIV.

We found that HPV 16 ranks first among 12 types of high-risk-HPV. Our data are consistent with those of other authors on the high frequency of HPV 16 in the groups of HIV-infected women. In a study conducted in St. Petersburg, the frequency of HPV 16 in HIV-infected women was 39.8\%. (16) In India, in HIV-infected women, HPV 16 was found in $58.5 \%$, in Colombia in $46.3 \%$, in Spain in $28 \%$ of cases. ${ }^{(20-22)}$

We compared the detection frequency of HPV 16 in women with HIV (our own data) and without HIV (literature data) living in Irkutsk (Eastern Siberia region). The frequency of HPV 16 type in Irkutsk was 33\%.(17) The incidence of HPV 16 in the group of HIV-infected women in our study was $51.6 \%$, which was 1.5 times higher $(\mathrm{z}=1.976 ; P=0.048)$. 
A comparative analysis of the detection frequency of HPV types 33, 35 and 18 in groups of women with and without HIV living in Irkutsk showed some differences. The detection frequency of HPV 33 and HPV 35 in the group of HIV-infected women, according to the results of our study, was 48.4 and $38.7 \%$, respectively. According to other authors, the frequency of detection of HPV 33 and HPV 35 among women aimed at HPV testing was 16.8 and $5.1 \%$, respectively. ${ }^{(17)}$ Statistically significant differences were obtained by comparing the frequency of HPV 33 and HPV 35 between these groups of women $[(\mathrm{z}=4.281 ; P<0.001)$ and $(\mathrm{z}=7.249 ; P<0.001)$, respectively]. The frequency of detection of HPV 18 in women with HIV, according to the results of our study, was $22.6 \%$, and the frequency of detection of HPV 18 among women aimed at HPV testing was $6.3 \% .{ }^{(17)}$ Statistically significant differences were obtained by comparing the frequency of HPV18 between these groups of women $(\mathrm{z}=3.171 ; P=0,002)$.

Our study showed that after HPV 16, HPV33 and HPV 35 ranked the second and third, respectively, among 12 types of high-risk HPV. HPV 58 was the fourth, and both HPV 18 and 52 were the fifth. In other countries, according to the literature data, different types of HPV were in the second and third places after HPV 16 among HIV-infected women. So, in India, HPV 31 and HPV 56 were detected in $22.6 \%$ and $13.2 \%$ of HIVpositive women, respectively. ${ }^{(20)}$ In Colombia, HPV 31 and HPV 18 were found in $32.9 \%$ and $30.6 \%$, respectively. ${ }^{(21)}$ In the Bahamas, HPV 18 was the first and it was found in $34.9 \%$, HPV 58 and HPV 16 took the second and third places and were found in $30.2 \%$ and $27.9 \%$, respectively. ${ }^{(23)}$ In some countries, the frequency of HPV detection among HIV-infected women is slightly lower. Thus, in Korea, HPV 16 was detected in $10 \%,{ }^{(24)}$ and in Brazil only in $8 \%$ of HIV-positive women. ${ }^{(13)}$

\section{Conclusion}

The frequency of HPV detection was significantly higher in the group of HIV-infected women planning pregnancy than among women aimed at HPV testing and living in the same city $\left(\chi^{2}=12.59 ; \mathrm{df}=1 ; P=0,001\right)$. HIV-positive women had HPV combined with several types; on average, they were infected with three different types of HPV. More than half of the women with HIV were infected with HPV 16, which has the greatest carcinogenic risk. HPV 33 and HPV 35 ranked second and third in the frequency of HPV detection, which were found in $48.4 \%$ and $38.7 \%$ of HIV-infected women, respectively. The frequency of detection of HPV 18 in our study was $22.6 \%$. LSIL and HSIL were statistically significant more in HIV-infected women with HPV than in HIV-infected women without HPV $(P=0.019)$.

HIV-infected women planning pregnancy and living in Irkutsk form a group at high-risk of HPV infection. It is necessary to monitor these patients for timely detection of HPV and for cervical screening.

\section{Competing Interests} interests.

\section{References}

1. Merli MG, Moody J, Mendelsohn J, Gauthier R. Sexual Mixing in Shanghai: Are Heterosexual Contact Patterns Compatible With an HIV/AIDS Epidemic? Demography. 2015 Jun; 52(3):919-42. doi: 10.1007/s13524-015-0383-4.

2. Mukandavire C, Walker J, Schwartz S, Boily MC, Danon L, Lyons C, et al. Estimating the contribution of key populations towards the spread of HIV in Dakar, Senegal. J Int AIDS Soc. 2018 Jul;21 Suppl 5(Suppl Suppl 5):e25126. doi: $10.1002 /$ jia2.25126.

3. Coates TJ. The Fight Against HIV Is a Fight for Human Rights: A Personal Reflection. J Acquir Immune Defic Syndr. 2019 Dec 1;82 Suppl 2(2):S91-S93. doi: 10.1097/ QAI.0000000000002165.

4. Belyaeva EV, Pervushina OA, Timofeeva EV, Leschenko OYa. [The incidence of high-risk oncogenic types of human papillomavirus in HIV-infected women of reproductive age living in the Irkutsk area]. Infectious Diseases. 2015;3(4):5761. [Article in Russian].

5. Prevention gap report. 2016. http://www.unaids.org. Accessed May 11, 2021.

6. Leshchenko O, Belyaeva E, Yershova O, Atalyan A, Timofeeva $E$. The frequency of human papilloma virus in women of reproductive age with infection. Journal of Lower Genital Tract Disease. 2017;21(2 S1): S39-S40.

7. Kolesnikova LI, Kolesnikov SI, Darenskaya MA, Grebenkina LA, Timofeeva EV, Leshchenko OY, et al. [Evaluation of the pro- and antioxidant status of women with HIV or coinfection]. Ter Arkh. 2016;88(11):17-21. doi: 10.17116/terarkh2016881117-21._[Article in Russian].

8. Kolesnikova LI, Darenskaya MA, Rashidova MA, Sholokhov LF, Grebenkina LA, Leschenko OYa, Timofeeva EV. [Evaluation of oxidative stress in women with HIV mono- and coinfection]. Infectious Disease. 2016;14(S1):138. [Article in Russian].

9. Burd EM. Human papillomavirus and cervical cancer. Clin Microbiol Rev. 2003 Jan;16(1):1-17. doi: 10.1128/ cmr.16.1.1-17.2003.

10. Bosch FX, de Sanjosé S. The epidemiology of human papillomavirus infection and cervical cancer. Dis Markers. 2007;23(4):213-27.

11. WHO. Human papillomavirus (HPV) and cervical cancer. Available from: https://www.who.int/news-room/fact-sheets/ detail/human-papillomavirus-(hpv)-and-cervical-cancer

12. Looker KJ, Rönn MM, Brock PM, Brisson M, Drolet M, Mayaud P, Boily MC. Evidence of synergistic relationships between HIV and Human Papillomavirus (HPV): systematic reviews and meta-analyses of longitudinal studies of HPV acquisition and clearance by HIV status, and of HIV acquisition by HPV status. J Int AIDS Soc. 2018 Jun;21(6):e25110. doi: $10.1002 / \mathrm{jia} 2.25110$.

13. Rocha-Brischiliari SC, Gimenes F, de Abreu AL, Irie MM, Souza RP, Santana RG, et al. Risk factors for cervical HPV infection and genotypes distribution in HIV-infected South Brazilian women. Infect Agent Cancer. 2014 Feb 11;9(1):6. doi: 10.1186/1750-9378-9-6.

14. Ford JH, Li M, Scheil W, Roder D. Human papillomavirus infection and intrauterine growth restriction: a data-linkage study. J Matern Fetal Neonatal Med. 2019 Jan;32(2):279-285. doi: $10.1080 / 14767058.2017 .1378330$.

15. Sverdlova ES, Dianova TV, Sofina SS, Kulinich SI. [The etiopathogenetic approaches to diagnostics of cervix uteri 
diseases in immunocompromised women]. Siberian Medical Journal (Irkutsk). 2009;7:87-90. [Article in Russian].

16. Martirosyan MM, Niauru DA, Stepanova YeV, Samarina AV. [Specificities of papilloma virus infection of cervix uteri in HIV-infected women in Saint-Petersburg]. HIV Infection and Immunosuppression. 2012;4(1):51-56. [Article in Russian]. 17. Shipulina OYu, Maksimova EG. [The prevalence of HPV infection of high oncogenic risk among men and women in Moscow and Irkutsk]. Proceedings of the VIII All-Russian Scientific and Practical Conference with International Participation "Molecular Diagnostics-2014", March 18-20, 2014, Moscow. M.; 2014:198-200. [Article in Russian]. 18. Shipulina OYu, Popova AA, Kravchenko AV, Deulina MO, Dmitryukova MYu, Romanyuk TN. [Prevalence of high oncogenic risk genotypes of human papillomavirus in HIV-positive and HIV-negative females]. Infectious Disease. 2016;14(4):26-30. doi: 10.20953/1729-9225-2016-4-26-30. [Article in Russian].

19. Marochko KV, Artymuk NV. [Features of papillomavirus infection in human immunodeficiency virus-infected women]. Fundamental and Clinical Medicine. 2017;2(3):35-41. [Article in Russian].

20. Joshi S, Babu JM, Jayalakshmi D, Kulkarni V, Divate $\mathrm{U}$, Muwonge $\mathrm{R}$, et al. Human papillomavirus infection among human immunodeficiency virus-infected women in Maharashtra, India. Vaccine. 2014 Feb 19;32(9):1079-85. doi: 10.1016/j.vaccine.2013.12.060.

21. Camargo M, Soto-De Leon SC, Munoz M, Sanchez R, Peña-Herrera D, Pineda-Peña AC, et al. Human papillomavirus detection in women with and without human immunodeficiency virus infection in Colombia. BMC Cancer. 2014 Jun 18;14:451. doi: 10.1186/1471-2407-14-451.

22. Videla S, Darwich L, Cañadas MP, Paredes R, Tarrats A, Castella E, et al. HIV-HPV Study Group. Epidemiological data of different human papillomavirus genotypes in cervical specimens of HIV-1-infected women without history of cervical pathology. J Acquir Immune Defic Syndr. 2009 Feb 1;50(2):168-75. doi: 10.1097/QAI.0b013e3181938e63.

23. Dames DN, Blackman E, Butler R, Taioli E, Eckstein S, Devarajan K, et al. African Caribbean Cancer Consortium. High-risk cervical human papillomavirus infections among human immunodeficiency virus-positive women in the Bahamas. PLoS One. 2014 Jan 23;9(1):e85429. doi: 10.1371/ journal.pone.0085429.

24. Park EK, Cho H, Lee SH, Lee SG, Lee SY, Kim KH, et al. Human papillomavirus prevalence and genotype distribution among HIV-infected women in Korea. J Korean Med Sci. 2014;29(1):32-7. doi: 10.3346/jkms.2014.29.1.32 